\title{
Effects of Domain Size on Physical Properties of a Thermotropic Liquid Crystalline Polyester
}

\author{
Dong Jo LYOU and Sung Chul Kim \\ Department of Chemical Engineering, Korea Advanced Institute of Science and Technology, \\ 373-1 Kusong, Yusong, Taejon 305-701, Korea
}

(Received October 11, 1996)

\begin{abstract}
To see the effect of domain size on the physical properties of thermotropic liquid crystalline polyester, poly[(phenylsulfonyl)-p-phenylene 1,8-octamethylene bis(4-berzoate)] (NP8) having low isotropization temperature at $178^{\circ} \mathrm{C}$, was synthesized via solution polymerization. Previous thermal histories were erased by treating at isotropic temperature at $200^{\circ} \mathrm{C}$ and the LC domain size was controlled by annealing at liquid crystal state temperature, at $170^{\circ} \mathrm{C}$. LC domains grew with annealing time and the domain growth rate was scaled as $d-t^{0.19}$ at $170^{\circ} \mathrm{C}$. The effect of the LC domain size on the crystallization rate was investigated. Crystallization temperature of $110^{\circ} \mathrm{C}$ was chosen since the growth rate showed maximum at that temperature. Three crystal melting peaks were observed on the crystallized sample. Avrami treatment and WAXD analysis for the three different crystal structures revealed that the high temperature melting crystal has higher degree of orientation than the low temperature melting crystal. It was found that the NP8 with large domain size had the faster crystallization rate and higher isotropization temperature. The effect of domain size on the transient rheological properties showed that the larger domain size had smaller stress overshoot and $N_{1}$ overshoot for the transient shear flow. The effect of domain size on the steady state rheological properties showed that the larger domain size had smaller steady state $N_{1}$ values at low shear rate region.
\end{abstract}

KEY WORDS Thermotropic Polyester / Thermal History / Liquid Crystal Domain / Domain Growth Rate / Crystallization Rate / Rheological Properties /

It is well known that the structure of the liquid crystalline polymer (LCP) is influenced by its previous thermal and deformational histories. ${ }^{1-12}$ LC state, containing disclinations, i.e., discontinuities in molecular orientation, has excess free energy density generated from director distortions around the disclinations. ${ }^{13}$ The excess free energy density can be relaxed by annealing process that leads to lower disclination density and larger domain size. However, since the relaxation of the LCP is a kinetic process and LCPs have quite a long relaxation time, different domain size would be obtained depending on the thermal and deformational histories.

The difference in domain size might result in different physical properties of the LCP, such as thermal and rheological properties. Larson and $\mathrm{Doi}^{14}$ suggested a constitutive equation set for the textured lyotropic LCP system, which predicts the changes of rheological properties and defect density annihilation rate. However, the suggested equation set can not explain the effect of domain size on the rheological properties. A simple modification of the Larson and Doi's constitutive equation set by $\mathrm{Kim}^{15}$ can predict the shear thinning behavior at low shear rate region and the domain size effect on the rheological properties. Figure 1 shows the changes of steady state rheological properties with the variation of disclination line. Since the equation set can be applied to lyotropic LCPs, five physical parameters concerning with elasticity constant, molecular concentration, viscosity, hydrodynamic intensity and domain size are required for the simulation. However, to see the domain size effect four parameters except for the domain size were set to moderate values. In Figure 1, the disclination line $(l)$ is reciprocally proportional to the square of domain size. Shear thinning behavior is predicted and larger domain size $\left(l_{2}\right)$ shows shear thinning behavior at lower shear rate region. Also, the first nor- mal stress difference $\left(N_{1}\right)$ shows different trends depending on the domain size.

In this study, a thermotropic polyester, having low isotropization temperature, was synthesized via solution polymerization. To lower the thermal transition temperatures, flexible methylene unit and phenyl-sulfonyl group as a nonlinear structure were introduced into the repeating unit. The low isotropization temperature of the LCP made it possible to erase previous histories without noticeable thermal degradation. The domain size growth rate was studied by light scattering experiment and the domain size was scaled as $t^{n}$. To see the effect of domain size on the physical properties, the crystallization
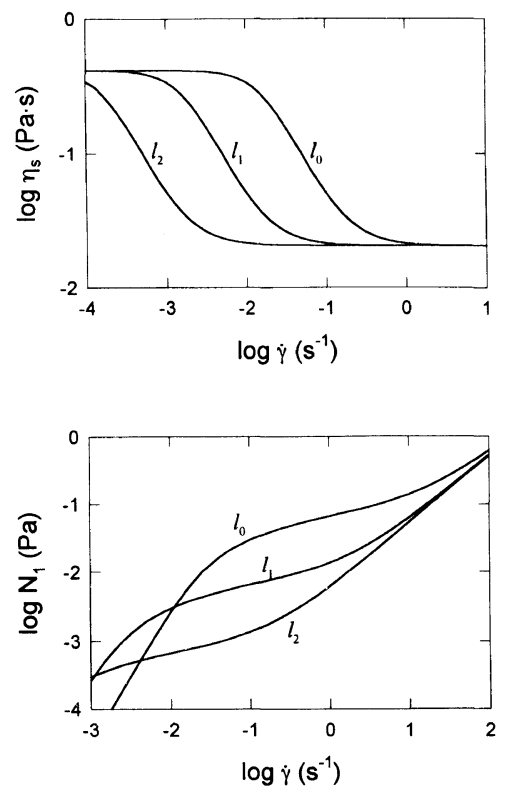

Figure 1. Changes of steady state rheological properties at low shear rate region with the variation of initial disclination lines $\left(l_{0}>l_{1}>l_{2}\right)$. 
rate, transient rheological properties and steady state rheological properties were measured on samples having different annealing time at LC state temperature.

\section{EXPERIMENTAL}

\section{Materials}

The liquid crystalline polymer used in this study was poly[(phenylsulfonyl)-p-phenylene 1,8 -octamethylene bis(4-oxybenzoate)] with following chemical structure.

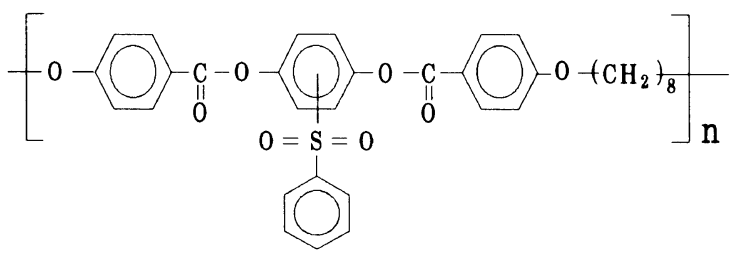

It was synthesized via solution polymerization and it will be referred to as NP8, hereafter. The details of the synthesis procedure were given by Furukawa and Lenz ${ }^{16}$ and a similar synthesis scheme was empolyed as described in our previous study. ${ }^{17}$

\section{Characterization}

The weight average molecular weight of the NP8 determined by GPC was 17000 with the polydispersity index of 1.42. The chemical structure of the synthesized NP8 was identified by a Bomen FT-IR and further confirmed by ${ }^{13} \mathrm{C}$ NMR $(200 \mathrm{MHz})$ in perdeuterated dimethyl sulfoxide (DMSO).

\section{Differential Scanning Calorimetry (DSC)}

Thermal transition temperatures of the NP8 were determined by DSC (du Pont 2010), which was calibrated with an indium standard. All DSC runs were carried out under nitrogen atmosphere with the heating rate of $10^{\circ} \mathrm{Cmin}^{-1}$. The DSC run of the NP8 showed that the glass transition temperature was $90^{\circ} \mathrm{C}$ and the isotropization temperature was $178^{\circ} \mathrm{C}$.

\section{Light Scattering Experiment}

Light scattering apparatus with a $\mathrm{He}-\mathrm{Ne}(\lambda=632.8$ $\mathrm{nm})$ light source was used to detect the scattered light intensity of the NP8 during isothermal annealing process. Samples were prepared by casting $0.7 \mathrm{wt} \% 1,1,2,2-$ tetrachloroethane solution on microscope coverglasses. Since the isotropization temperature was $178^{\circ} \mathrm{C}$, prepared samples were treated at $200^{\circ} \mathrm{C}$ for 5 min to keep the samples at isotropic state and then quenched to $170^{\circ} \mathrm{C}$, which is LC state temperature. The scattered light intensity was measured at $170^{\circ} \mathrm{C}$ with annealing time to study the LC domain growth kinetics.

\section{Optical Microscopy}

The optical textures of the NP8 were observed on a hot stage (Mettler FP-2) attached to a polarizing microscope (Leitz Model Laborlux). Sample preparation method was identical with that of the light scattering experiment. The samples were isotropically treated at $200^{\circ} \mathrm{C}$ for $5 \mathrm{~min}$ and then rapidly transferred to predetermined LC state temperature, $170^{\circ} \mathrm{C}$. The polarized micrographs were taken with annealing time.

\section{Crystallization Kinetics}

To see the effect of domain size on the crystallization rate, samples were treated at $200^{\circ} \mathrm{C}$ for $5 \mathrm{~min}$ to erase previous thermal histories and then quenched in liquid nitrogen. To make domain size difference, one sample was annealed at $170^{\circ} \mathrm{C}$ for $30 \mathrm{~min}$ and the other sample was maintained as quenched. Two samples of different LC domain size were crystallized at $110^{\circ} \mathrm{C}$ for various crystallization times. After crystallization, samples were quenched in liquid nitrogen and DSC runs were carried out. The detailed effect of the domain size on the crystallization rate was investigated by changing the annealing time from $30 \mathrm{~s}$ to $50 \mathrm{~min}$. The crystallization temperature was $110^{\circ} \mathrm{C}$ and the crystallization time was fixed at 6 hours.

\section{Rheological Measurement}

Rheological properties of the NP8 were investigated with Rheometric Mechanical Spectrometer (RMS-800). Cone and plate fixture with the diameter of $25 \mathrm{~mm}$ and the cone angle of 0.1 radian was used. The gap size was set to $100 \mu \mathrm{m}$ and the experiments were conducted under nitrogen atmosphere. To investigate the effect of domain size on the transient rheological properties, samples were isotropically treated at $200^{\circ} \mathrm{C}$ for $5 \mathrm{~min}$ and then cooled to $170^{\circ} \mathrm{C}$. Domain size was controlled by annealing time, $1 \mathrm{~min}, 5 \mathrm{~min}$ and $30 \mathrm{~min}$. After the fixed annealing time, transient shear flow with $\dot{\gamma}=0.05 \mathrm{~s}^{-1}$ was applied and stress and first normal stress difference $\left(N_{1}\right)$ were measured.

To investigate the effect of the domain size on the steady state rheological properties, steady state viscosities and steady state first nomral stress differences were measured under various shear rates. After isotropic treatment at $200^{\circ} \mathrm{C}$ for $5 \mathrm{~min}$, domain size was controlled at $160^{\circ} \mathrm{C}$ for $1 \mathrm{~min}$ and $30 \mathrm{~min}$. The experiment temperature was lowered from $170^{\circ} \mathrm{C}$ to $160^{\circ} \mathrm{C}$ to measure the steady state rheological properties at much lower shear rates. Dynamic tests under strain amplitude of 0.1 and frequency of $1 \mathrm{rad} / \mathrm{sec}$ showed that the complex viscosity at $170^{\circ} \mathrm{C}$ was $680 \mathrm{~Pa} \mathrm{~s}^{-1}$ and the complex viscosity at $160^{\circ} \mathrm{C}$ was $910 \mathrm{~Pa} \mathrm{~s}^{-1}$. The rheological measurement at $160^{\circ} \mathrm{C}$ showed better response at low shear rates.

\section{Wide-Angle X-Ray Diffraction (WAXD)}

WAXD experiments were carried out on powder samples, using a Rigaku X-ray generator operating at $40 \mathrm{kV}$ and $45 \mathrm{~mA}$ ( $\mathrm{Cu}-K_{\alpha}$ radiation, filtered by a $\mathrm{Ni}$ foil). A D/MAX-IIIC powder diffractometer was used to measure the diffractions of the sample. The scanning angle range $(2 \theta)$ was $2-40^{\circ}$ with scanning rate of $4^{\circ}$ $\min ^{-1}$.

For the experiment, samples were isotropically treated at $200^{\circ} \mathrm{C}$ for $5 \mathrm{~min}$ and then crystallized at $110^{\circ} \mathrm{C}$ for 20 hours and at $140^{\circ} \mathrm{C}$ for 50 hours, respectively. Crystallized samples were quenched in liquid nitrogen and were ground to powders before measurement.

\section{RESULTS AND DISCUSSION}

Domain Growth Kinetics of the NP8

Figure 2 shows LC texture growth of the NP8 during 


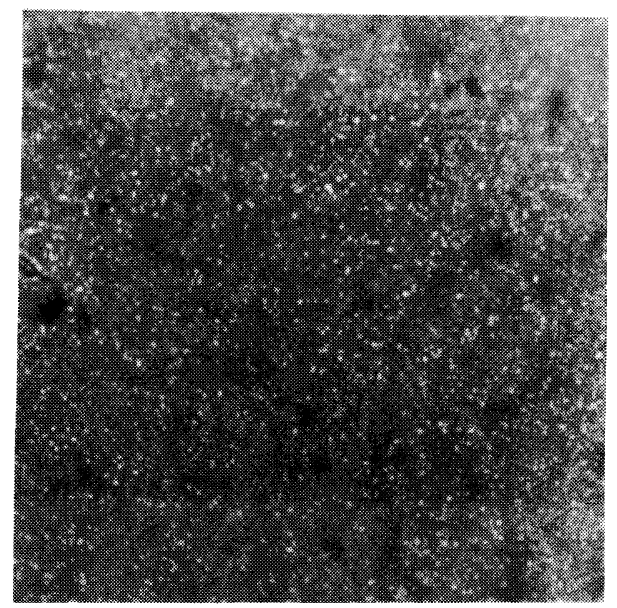

(a) 0

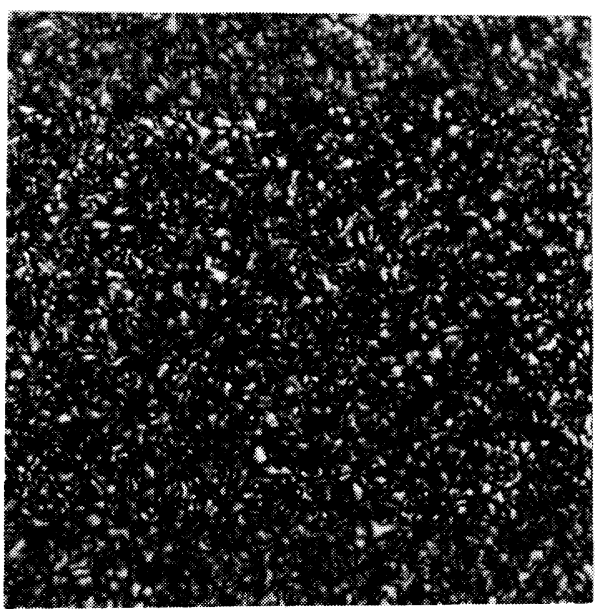

(c) $5 \mathrm{~min}$

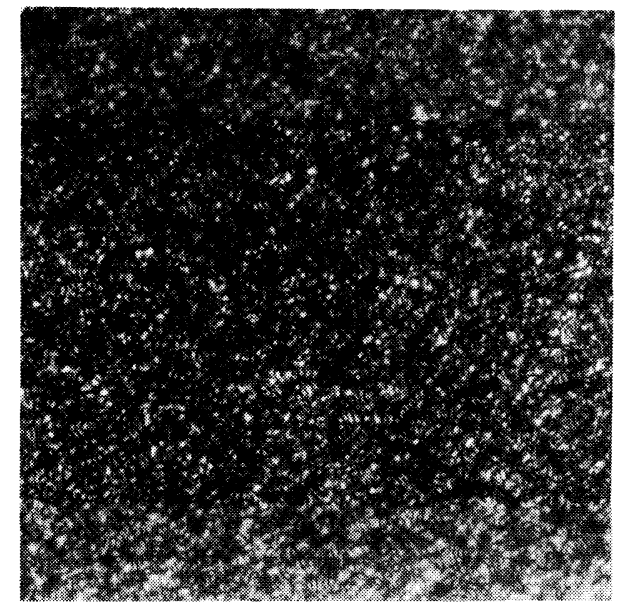

(b) $1 \mathrm{~min}$

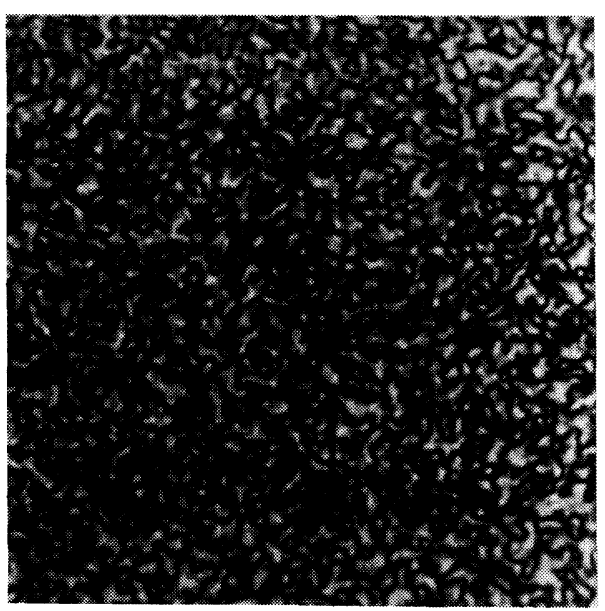

(d) $30 \mathrm{~min}$

\section{$\overline{20 \mu \mathrm{m}}$}

Figure 2. Polarized micrographs of the NP8 as a function of annealing time at $170^{\circ} \mathrm{C}$.

isothermal annealing at $170^{\circ} \mathrm{C}$. The sample was isotropically treated at $200^{\circ} \mathrm{C}$ and then quickly transferred to predetermined LC state temperature at $170^{\circ} \mathrm{C}$. The annealing time of 0 in Figure 2(a) indicates a quenched sample from $200^{\circ} \mathrm{C}$ to liquid nitrogen. The sample showed typical nematic schlieren texture and it grew with the annealing time. The growing of the LC texture indicated that number density of disclination decreased and LC domain size increased, which indicated that the molecular ordering in LCP increased with the annealing time. To quantify the LC domain growth rate, light scattering experiment was conducted. Figure 3 shows the scattered light intensity of the NP8 during isothermal annealing at $170^{\circ} \mathrm{C}$, where $\theta$ is the scattering angle and $q$ is the magnitude of the scattering vector. The peak maximum that is related to the domain size shifted to lower angles with increasing annealing time.

According to the light scattering model proposed by Hashimoto and co-workers, ${ }^{18}$ the characteristic domain size (domain correlation length; $d$ ) is correlated with the magnitude of the scattering vector at maximum intensity $\left(q_{\max }\right)$, corresponding to $\theta_{\max }$.

$$
d \sim \frac{2 \pi}{q_{\max }}
$$

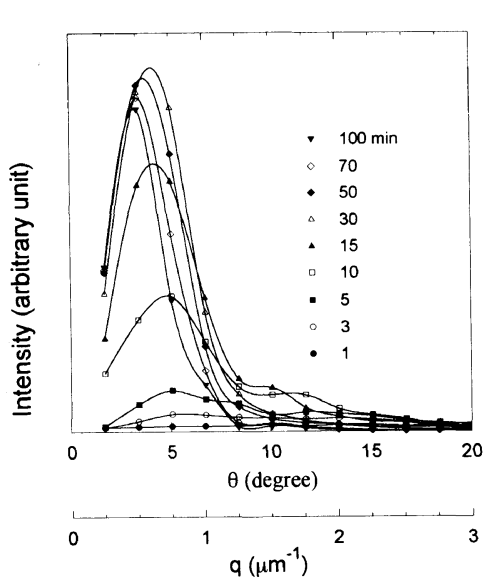

Figure 3. Scattered light intensity distributions measured at $170^{\circ} \mathrm{C}$.

$$
q_{\max }=\frac{4 \pi}{\lambda} \sin \left(\frac{\theta_{\max }}{2}\right)
$$

where $\lambda$ is the wavelength of the incident light.

Therefore, the shift of the maximum intensity to lower scattering angles indicated that the domain size grew with increasing annealing time. The growth rate of the domain size could be scaled ${ }^{19}$ as $d-t^{n}$, where $t$ is the 


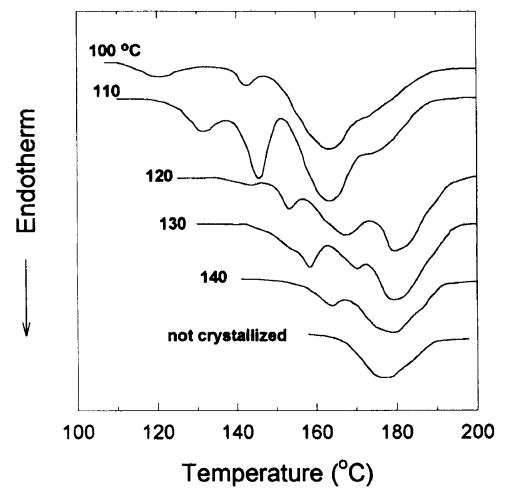

Figure 4. DSC curves of the NP8, crystallized for 15 hours at indicated temperature.

annealing time and $n$ is the scaling exponent. Domain sizes obtained from light scattering experiment were plotted against annealing time to get the scaling exponent of 0.19 . The domain sizes after annealing time of 0 , $1 \mathrm{~min}, 5 \mathrm{~min}$, and $30 \mathrm{~min}$ were $1.3 \mu \mathrm{m}, 3.1 \mu \mathrm{m}, 4.2 \mu \mathrm{m}$, and $5.9 \mu \mathrm{m}$, respectively.

\section{The Effect of LC Domain Size on the Crystallization of NP8}

The thermal transition temperatures of the NP8 were significantly affected by the thermal treatment. Figure 4 shows the DSC curves of the NP8 that had been crystallized at indicated temperatures for 15 hours, and a curve of quenched sample from $170^{\circ} \mathrm{C}$. Before the crystallization process, samples were isotropically treated at $200^{\circ} \mathrm{C}$ and then annealed at $170^{\circ} \mathrm{C}$ for $30 \mathrm{~min}$ to allow the LC domain growth. The quenched sample showed only the isotropization peak, which indicated that no crystallization occurred during quenching and heating process. Even with a moderate cooling rate $\left(5^{\circ} \mathrm{C} \mathrm{min}^{-1}\right)$ or with a slow cooling rate $\left(0.1^{\circ} \mathrm{C} \mathrm{min}{ }^{-1}\right)$, no crystal melting peak was detected. Regarding the phenylsulfonyl group in NP8, the rigid and bulky side group might have made it difficult to crystallize during cooling and heating process. Consequently, the origin of crystal formation of the NP8 was not from the fast transition process but from the slow transition process. ${ }^{20}$ After crystallizing at $100^{\circ} \mathrm{C}$ for 15 hours, four endothermic peaks including a isotropization peak were detected. The three endothermic peaks at $120^{\circ} \mathrm{C}, 142^{\circ} \mathrm{C}$, and $165^{\circ} \mathrm{C}$ were crystal melting peaks and the other peak at $178^{\circ} \mathrm{C}$ was isotropization peak, which was overlapping with the $165^{\circ} \mathrm{C}$ melting peak. As the crystallization temperature was increased to $110^{\circ} \mathrm{C}, 120^{\circ} \mathrm{C}$, and $130^{\circ} \mathrm{C}$, crystal melting tempeatures were also increased. At crystallization temperature of $140^{\circ} \mathrm{C}$, only one crystal melting peak at $163^{\circ} \mathrm{C}$ was observed with a nematicisotropic transition peak at $178^{\circ} \mathrm{C}$. At higher crystallization temperatures such as $150^{\circ} \mathrm{C}, 160^{\circ} \mathrm{C}$, and $170^{\circ} \mathrm{C}$, no crystal melting peak was detected for the 15 hours of crystallization time. Therefore, it can be said that the crystallization rate was very low at $150^{\circ} \mathrm{C}$ and $160^{\circ} \mathrm{C}$. Another observation in Figure 4 was that the crystallization at $110^{\circ} \mathrm{C}$ had the highest heat of fusion, which implied the fastest crystallization rate.

The effect of the LC domain size on the crystallization rate was studied at $110^{\circ} \mathrm{C}$ since the growth rate showed

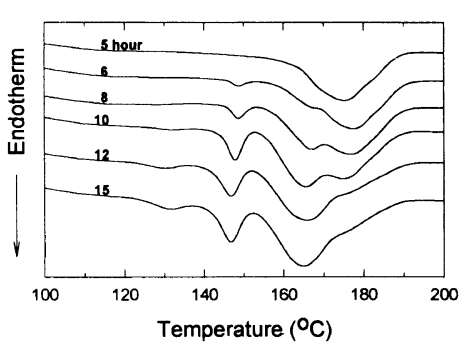

(a) Quenched

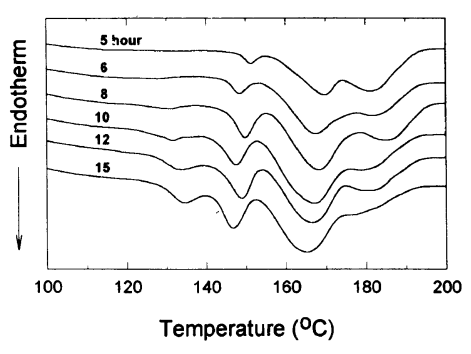

(b) $30 \mathrm{~min}$ annealed

Figure 5. DSC curves of the NP8 crystallized under following scheme. (a) Quenched: $200^{\circ} \mathrm{C}(5 \mathrm{~min}) ; 110^{\circ}$ (indicated time). (b) $30 \mathrm{~min}$ annealed: $200^{\circ} \mathrm{C}(5 \mathrm{~min}) ; 170^{\circ} \mathrm{C}(30 \mathrm{~min}) ; 110^{\circ} \mathrm{C}$ (indicated time).

maximum at that temperature. Figure 5 shows DSC curves of the samples crystallized for different times at $110^{\circ} \mathrm{C}$ with different domain size. In Figure 5(a) the quenched sample had the smallest domain size of $1.3 \mu \mathrm{m}$ and in Figure 5(b) the annealed sample for $30 \mathrm{~min}$ at $170^{\circ} \mathrm{C}$ had domain size of $5.9 \mu \mathrm{m}$. For the quenched sample, first crystal melting peak having highest melting tempeature $\left(T_{\mathrm{m}}\right)$ at $168^{\circ} \mathrm{C}$ was detected after 5 hours of crystallization time and second crystal melting peak having intermediate $T_{\mathrm{m}}$ at $149^{\circ} \mathrm{C}$ was detected after 6 hours of crystallization time and finally third crystal melting peak having lowest $T_{\mathrm{m}}$ at $130^{\circ} \mathrm{C}$ was observed after 12 hours of crystallization time. For the $30 \mathrm{~min}$ annealed sample, first crystal melting peak was detected after 3 hours of crystallization time and second crystal melting peak was detected after 5 hours of crystallization time and finally third crystal melting peak was observed after 8 hours of crystallization time. After being detected, each crystal melting peak grew with increasing crystallization time and the growth was leveled off after 20 hours of crystallization time because of the termination of crystallization. Comparison of the quenched sample and the $30 \mathrm{~min}$ annealed sample revealed that the 30 min annealed sample had the faster crystallization rate for all the three crystals. The faster crystallization rate could be explained as follows. The well ordered molecular structure (30 min annealed sample) would make it easier to crystallize than the poorly ordered structure (quenched sample) because the crystallization is an ordering process of the molecules.

To quantify the crystallization rate, DSC thermograms were divided into four endothermic peaks, three crystal melting peaks and one isotropication peak, and the growth rate of each peak was traced along the crystallization time.

Isothermal development of crystallinity in polymers has been described by the Avrami equation. ${ }^{21}$ The Avrami equation was given by following form. 


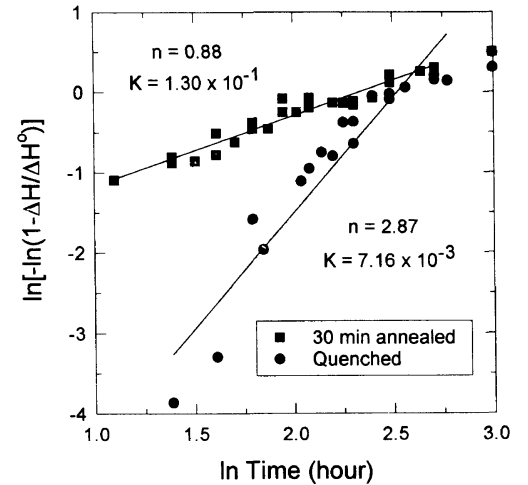

Figure 6. Avrami treatment of the crystallization kinetics for the first crystal.

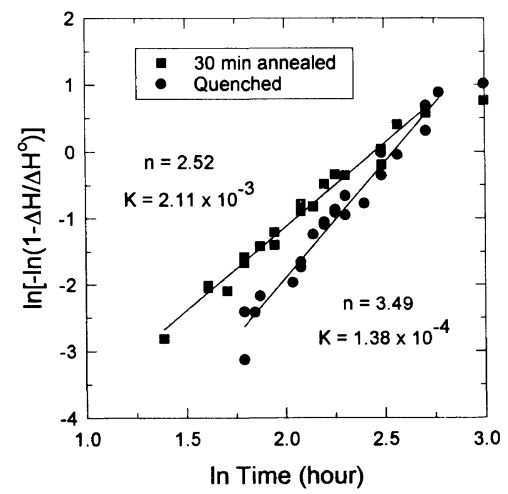

Figure 7. Avrami treatment of the crystallization kinetics for the second crystal.

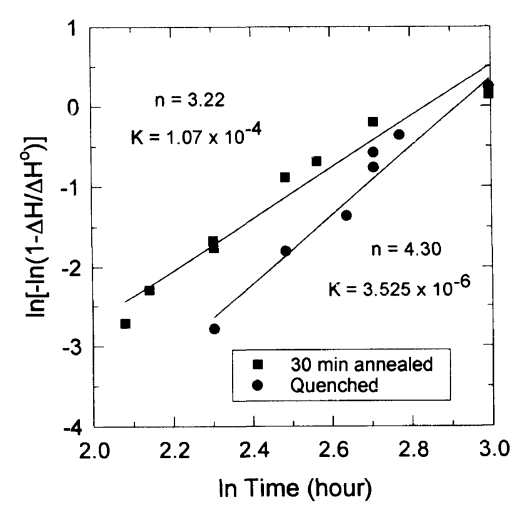

Figure 8. Avrami treatment of the crystallizatio kinetics for the third crystal.

$$
1-\theta=\exp \left(-K t^{n}\right)
$$

where $\theta$ is the fraction of crystallized polymer at time $t$, $K$ is the crystallization rate constant and $n$ is the Avrami exponent which indicates the mode of nucleation and crystal growth dimensions.

In Figure 6, Avrami treatment for the first crystal (having highest $T_{\mathrm{m}}$ ) shows that the $30 \mathrm{~min}$ annealed sample has large crystallization rate constant $(K)$ of $1.3 \times 10^{-1}$ and small Avrami exponent $(n)$ of 0.88 , while the quenched sample has $K$ value of $7.16 \times 10^{-3}$ and Avrami exponent of 2.87. This indicates that the $30 \mathrm{~min}$ annealed sample shows faster crystallization rate and one-dimensional crystal growth.

Avrami treatments for the second crystal and third crystal are shown in Figures 7 and 8. The crystallization

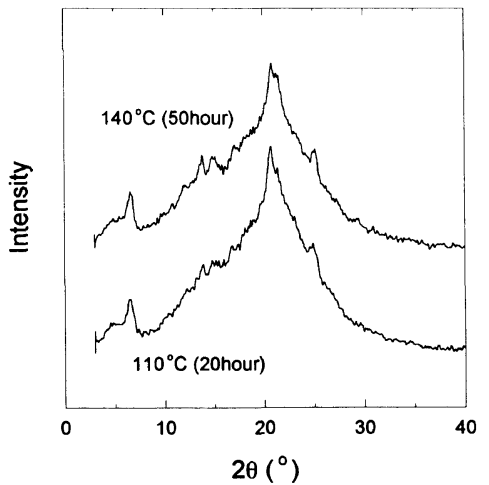

Figure 9. X-Ray diffraction patterns of the NP8, crystallized at $110^{\circ} \mathrm{C}$ $(20 \mathrm{~h})$ and $140^{\circ} \mathrm{C}(50 \mathrm{~h})$.

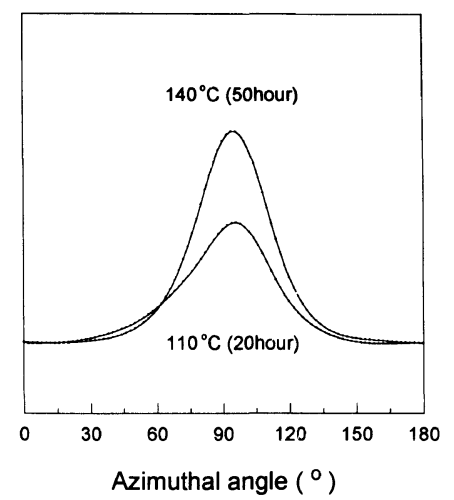

Figure 10. Azimuthal scanning at $2 \theta=20.6^{\circ}$ to measure the degree of orientation.

rate constant of the $30 \mathrm{~min}$ annealed sample was about 20 - 30 times higher than that of the quenched sample in all three crystal structures. Comparison of the Avrami treatments for the three crystals revealed that the third crystal (having lowest $T_{\mathrm{m}}$ ) had the lowest crystallization rate constant and the highest Avrami exponent. The higher value of Avrami exponent for the third crystal implies that the third crystal has the larger crystal growth dimensionality than the first and second crystals.

With the different melting temperatures and with the different crystal growth dimensionality, it can be assumed that each crystal has different lattice parameters. To check this assumption, one sample being crystallized at $140^{\circ} \mathrm{C}$ for 50 hours was prepared and compared with another sample crystallized at $110^{\circ} \mathrm{C}$ for 20 hours. The $140^{\circ} \mathrm{C}$ crystallized sample had only one crystal melting peak at $165^{\circ} \mathrm{C}$, while the $110^{\circ} \mathrm{C}$ crystallized sample had three crytal melting peaks at $132^{\circ} \mathrm{C}, 148^{\circ} \mathrm{C}$, and $165^{\circ} \mathrm{C}$. However, the X-ray diffraction patterns (Figure 9) showed the same diffraction peaks for the two samples. This result indicated that the two samples have the same lattice parameters, although the $110^{\circ} \mathrm{C}$ crystallized sample contained lower temperature melting crystals.

With the same lattice parameters and with different crystal growth dimensionality, it can be assumed that each crystal structure has difference in the degree of orientation. The third crystal, having larger crystal growth dimensionality, will have lower degree of orientation since the dimensionality of the molecular packing will increase with lower degree of orientation. To check this assumption degree of orientation was measured by azimuthal scanning. Figure 10 shows the 


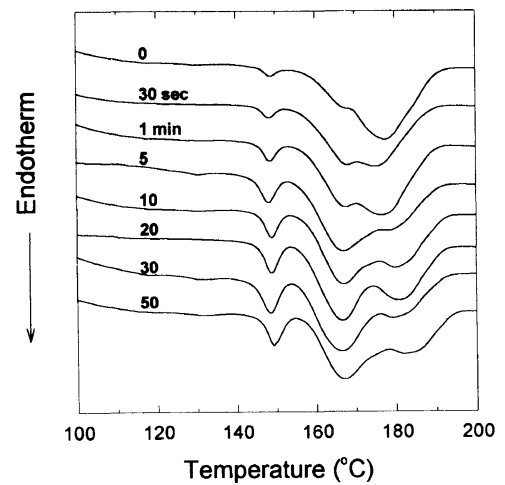

Figure 11. DSC curves of the NP8, crystallized at $110^{\circ} \mathrm{C}$ for 6 hour with different annealing time at $170^{\circ} \mathrm{C}$.

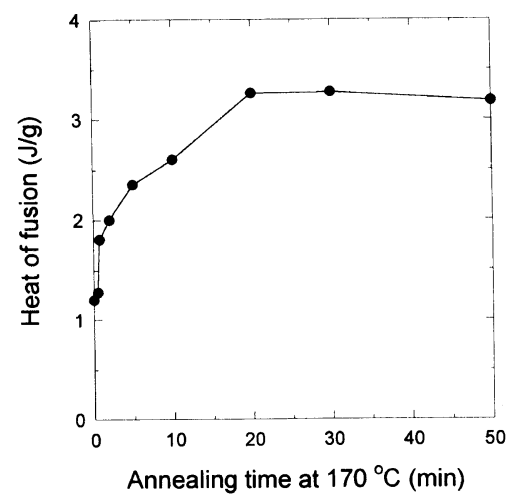

Figure 12. Comparison of crystallization rate with annealing time.

azimuthal scanning at $2 \theta=20.6^{\circ}$, the angle with the sharpest peak in the X-ray diffraction pattern (Figure 9). The broader peak for the $110^{\circ} \mathrm{C}$ crystallized sample indicated that the structure has lower degree of orientation as assumed.

To see the detailed effect of the LC domain size on the crystallization rate, domain size was controlled at $170^{\circ} \mathrm{C}$ from $30 \mathrm{~s}$ to $50 \mathrm{~min}$. Figure 11 shows DSC curves of the NP8 crystallized at $110^{\circ} \mathrm{C}$ for 6 hours with different annealing time at $170^{\circ} \mathrm{C}$. The crystal melting peaks grew with increasing annealing time. The heat of fusion (Figure 12) increased with increasing annealing time and leveled off after $20 \mathrm{~min}$ of annealing time. Also, the isotropization temperature increased with increasing annealing time and leveled off after 20 min of annealing time. As mentioned earlier, the well ordered molecular structure would make it easier to crystallize and make it more difficult to disrupt its LC structure.

\section{The Effect of LC Domain Size on the Rheological Prop- erties of the NP8}

To see the effect of domain size on the rheological properties, domain size was controlled at $170^{\circ} \mathrm{C}$ for $1 \mathrm{~min}, 5 \mathrm{~min}$, and $30 \mathrm{~min}$. All samples were isotropically treated at $200^{\circ} \mathrm{C}$ to erase previous histories and then temperature was lowered to $170^{\circ} \mathrm{C}$ to develop LC domain structure. After fixed time for domain growth, transient shear flow with $\dot{\gamma}=0.05 \mathrm{~s}^{-1}$ was applied and the shear stress and first normal stress difference $\left(N_{1}\right)$ were measured. In Figure 13, a large stress overshoot was observed and its magnitude decreased with increasing annealing time. Similar domain size effect was also observed
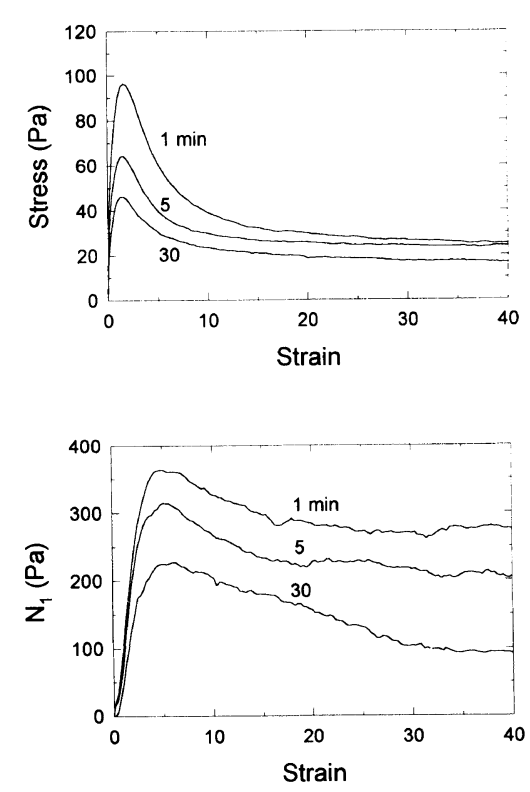

Figure 13. Transient behavior of stress and $N_{1}$ of the NP8, measured at $170^{\circ} \mathrm{C}$ with $\dot{\gamma}=0.05 \mathrm{~s}^{-1}$. Initial LC domain was developed for indicated time.

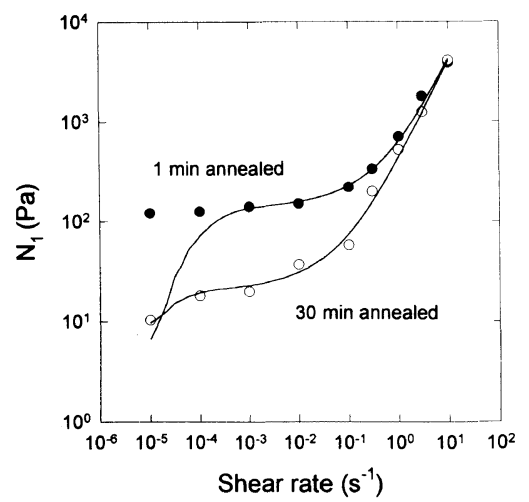

Figure 14. Comparison of steady state $N_{1}$ for different initial domain size.

for $N_{1}$ (Figure 13).

As described in the introductory part, domain size affects the rheological properties at low shear rate region. To see the effect of domain size on the steady state rheological properties, steady state viscosity and steady state $N_{1}$ were measured for various shear rates. The shear thinning behavior could not be measured due to the instrumental limit of measurement, while the steady state $N_{1}$ values could be measured even at $\dot{\gamma}=10^{-5} \mathrm{~s}^{-1}$. Figure 14 shows the measured steady state $N_{1}$ values for various shear rates with different domain size, $1 \mathrm{~min}$ annealed and $30 \mathrm{~min}$ annealed. The point values were measured data and the solid lines were theoretically expected data. Although rheological properties in Figure 1 were obtained from lyotropic LCP, thermotropic LCP, NP8 showed the similar behavior and its trend changed with different domain size.

\section{CONCLUSIONS}

The thermotropic LCP, poly [(phenylsulfonyl)-p-phenylene 1,8-octamethylene bis(4-benzoate)] (NP8), showed nematic schlieren texture and its glass transition tem- 
perature was $90^{\circ} \mathrm{C}$ and isotropization temperature was $178^{\circ} \mathrm{C}$. All sample were treated at $200^{\circ} \mathrm{C}$ for $5 \mathrm{~min}$ to erase previous thermal histories and LC domain size was controlled by annealing at $170^{\circ} \mathrm{C}$. LC domain grew with annealing time and the domain growth rate could be scaled as $d-t^{0.19}$ at $170^{\circ} \mathrm{C}$. The effects of initial domain size on the thermal and rheological properties were studied and the results were summarized as follows. (1) The NP8 with large initial domain size showed faster crystallization rate and higher isotropization temperature. (2) The Avrami treatments for the three different crystals showed that the NP8 with large initial domain size ( 30 min annealed sample) had about 20-30 times higher crystallization rate constant and lower Avrami exponent than the NP8 with small domain size (quenched sample). (3) Azimuthal scanning revealed that the higher temperature melting crystal had higher degree of orientation than the lower temperature melting crystal. (4) The NP8 with large initial domain size showed smaller stress overshoot and $N_{1}$ overshoot for the transient shear flow. (5) The NP8 with large initial domain size had smaller steady state $N_{1}$ values at low shear rate region as predicted by theory.

Acknowledgment. The authors are grateful to Korea Research Foundation for the financial support of this work.

\section{REFERENCES}

1. A. D. Gotsis and D. G. Baird, J. Rheol., 29, 539 (1985).

2. P. Moldenaers, G. Fuller, and J. Mewis, Macromolecules, 22, 960 (1989).

3. K. F. Wissbrun, J. Rheol., 25, 619 (1981).

4. W. R. Burghardt and G. R. Fuller, Macromolecules, 24, 2546 (1991).

5. P. Navard, J. Polym. Sci., Polym. Phys. Ed., 25, 1089 (1987).

6. Y. Takeuchi, Y. Shuto, and F. Yamamoto, Polymer, 29, 605 (1988).

7. E. Peuvrel and P. Navard, Macromolecules, 24, 5683 (1991).

8. E. Marsano, L. Carpaneto, and A. Ciferri, Mol. Cryst. Liq. Cryst., 158, 267 (1988).

9. P. Navard, J. Polym. Sci., Polym. Phys. Ed., 24, 435 (1986).

10. C. Viney and A. H. Windle, Polymer, 27, 1325 (1986)

11. B. Ernst and P. Narvard, Macromolecules, 22, 1419 (1989).

12. C. R. Fincher, Mol. Cryst. Liq. Cryst., 155, 559 (1988).

13. S. D. Hudson and E. L. Thomas, Chemtracts, 2, 73 (1991).

14. R. G. Larson and M. Doi, J. Rheol., 35, 539 (1991).

15. K. M. Kim and I. J. Chung, J. Rheol., 38, 1271 (1994).

16. A. Furukawa and R. W. Lenz, Macromol. Chem. Macromol. Symp., 2, 3 (1986).

17. Y. J. Lee and S. C. Kim, Polym. Adv. Tech., 5, 275 (1994).

18. T. Hashimoto, A. Nakai, and R. S. Stein, Macromolecules, 22, 429 (1989).

19. H. Nishimori and T. Nukii, J. Phys. Soc. Jpn., 58, 563 (1988).

20. S. Z. D. Cheng, Macromolecules, 21, 2475 (1988).

21. M. Avrami, J. Chem. Phys., 7, 1103 (1939); ibid., 8, 212 (1940); ibid., 9, 177 (1941). 